\title{
Massive hemoptysis in a pregnant woman: the first rare presentation of mitral valve stenosis
}

\author{
Fatemeh Hashemi ${ }^{1}$, Fariba Rezaeetalab ${ }^{2}$, Majid Jalalyazdi ${ }^{3}$ \\ ${ }^{1}$ Residency of Internal Medicine, School of Medicine, Mashhad University of Medical Sciences, Mashhad; ${ }^{2}$ Lung \\ Diseases Research Center, Mashhad University of Medical Sciences, Mashhad; ${ }^{3}$ School of Medicine, Mashhad \\ University of Medical Sciences, Mashhad, Iran
}

\begin{abstract}
Massive hemoptysis is one of the rare manifestations of mitral valve stenosis. Massive hemoptysis is considered as a potentially life threatening that frequently needs emergency procedures. A 43year-old pregnant woman presented with coughing and massive hemoptysis. She was diagnosed severe rheumatic mitral stenosis. The patient underwent percutaneous transluminal mitral valvuloplasty (PTMC). Before ICU admission and hospitalization, she was healthy, without any past medical history and complaints.
\end{abstract}

\section{Introduction}

Hemoptysis is a frequent manifestation in medicine and requires urgent approaches. The causes of hemoptysis are multiple and diverse. Massive hemoptysis is one of the medical emergencies with different etiology [1]. Bronchiectasis, tuberculosis and bronchogenic carcinoma are still demonstrated to be the most common causes of

Correspondence: Fariba Rezaeetalab, Lung Diseases Research Center, Mashhad University of Medical Sciences, Mashhad, Iran.

E-mail: rezaitalabf@mums.ac.ir

Authors' contributions: FR, MJ, study concept and design; FH, developed the theory and performed the computations. All authors investigated [a specific aspect] and supervised the findings of this work. All authors discussed the results and contributed to the final manuscript. All authors agree to be accountable for all aspects of the work.

Conflict of interest: The authors have no conflict of interest.

Key words: Massive hemoptysis; pregnant woman; mitral valve stenosis.

Received for publication: 23 November 2019.

Accepted for publication: 6 April 2020.

${ }^{\circ}$ Copyright: the Author(s), 2020

Licensee PAGEPress, Italy

Monaldi Archives for Chest Disease 2020; 90:1200

doi: 10.4081/monaldi.2020.1200

This article is distributed under the terms of the Creative Commons Attribution Noncommercial License (by-nc 4.0) which permits any noncommercial use, distribution, and reproduction in any medium, provided the original author(s) and source are credited. massive hemoptysis [2]. Massive lethal hemoptysis is a rare initial presentation of mitral valve stenosis. The most common cause of |mitral valve stenosis is rheumatic disease $[3,4]$.

\section{Case Report}

A 43-year-old gravida 3 para 2 pregnant woman with 25 -week gestational age was referred to our hospital due to coughing and hemoptysis for 5 days. The patient was completely healthy before hemoptysis with no disease and past medical history. She did not have fever, chills, purulent sputum, lower extremity swelling, shortness of breath, chest pain and skin rash. She was no smoker and denied every illicit drug, opium and alcohol consumption. She was admitted to ICU because of massive pulmonary hemorrhage. Up on presentation she was no acute distress and was normal mental status. Vital signs on admission revealed a temperature of $98.4^{\circ} \mathrm{F}$, heart rate of 88 per min, blood pressure of $144 / 80 \mathrm{mmHg}$, respiratory rate of 16/min while saturating $89 \%$ breathing ambient air. There was a sinus tachycardia, a prominent $\mathrm{S} 1$, split $\mathrm{S} 2$ with prominent $\mathrm{P} 2$, and a decrescendocrescendo diastolic murmur loudest at the apex. Pulmonary exam revealed bibasilar crackles. Her abdomen was soft and non-tender without lymphadenopathy, hepatomegaly and splenomegaly. There was no cyanosis or clubbing of the extremities. Complete blood count revealed: WBC of 7.200, Hb of 12, Hct of 38.1, PLT of 318000. PTT was 27, PT was 11.9 seconds, INR was 1.1. Hepatic panel was normal with an AST of $27 \mathrm{U} / \mathrm{L}$, ALT of $23 \mathrm{U} / \mathrm{L}$, Alkalin phosphatase of 60 $\mathrm{U} / \mathrm{L}$ and total bilirubin of $0.9 \mathrm{mg} / \mathrm{dL}$; urea: 12 and creatinin: 0.8 . Urine analysis was normal. ECG revealed sinus tachycardia. Portable A-P plain chest $\mathrm{x}$-ray represented slightly right paracardiac prominent opacity (Figure 1). So, with deterioration of the patient's condition, increased airway bleeding and loss of oxygen saturation, immediately double lumen intubation inserted and attached to the mechanical ventilator. Emergent transthoracic echocardiography showed very severe rheumatic mitral stenosis, with mitral valve area (MVA): 0.7 $\mathrm{cm}^{2}$ and trans mitral mean pressure gradient (MPG) of $33 \mathrm{mmHg}$ at HR: $120 / \mathrm{min}$. There was mild to moderate mitral insufficiency. Left ventricle had normal size with eject fraction: $55 \%$. Severe pulmonary hypertension was noted, with systolic pulmonary artery pressure, estimated as $105 \mathrm{mmHg}$, using tricuspid regurgitation Doppler signal (Figure 2 A-D).

The patient underwent percutaneous transluminal mitral valvuloplasty (PTMC) instantly. Echo study was repeated after PTMC. Anterolateral commissure was open; MVA was increased to $\left(1.2 \mathrm{~cm}^{2}\right)$ with significant decrease in MPG $(\# 11 \mathrm{mmHg}$, at HR: $74 / \mathrm{min})$ and systolic pulmonary artery pressure $(\# 45 \mathrm{mmHg})$ (Figure 3 A-D). 
Hemoptysis was dramatically stopped then the patient's life was saved from this terrible situation.

\section{Discussion}

Two directions of correct and prompt exposure to hemoptysis are very important. First, its differential diagnosis of hemoptysis is very widespread, the second, massive hemoptysis is associated with immediate death, hence, urgent diagnosis and treatment must be considered [2]. Although the rheumatic mitral valve stenosis is low in Europe and advanced countries, the prevalence of rheumatic diseases in the rest of the world and with a new wave of immigration is expected $[3,4]$.

Cardiac diseases occur in $2-4 \%$ of pregnancies and rheumatic mitral disease is the most common acquired heart disease in pregnancy. Pregnant women with mitral stenosis are the high-risk group [4,5]. Mitral valve disease in pregnancy tends to worsen due to increased heart rate and cardiac out put. Hemodynamic changes in mitral stenosis during pregnancy are challenging issue [5].

Mitral valve stenosis is associated with high mother's and fetus's mortality. One of the rare presentations of mitral stenosis is a frank

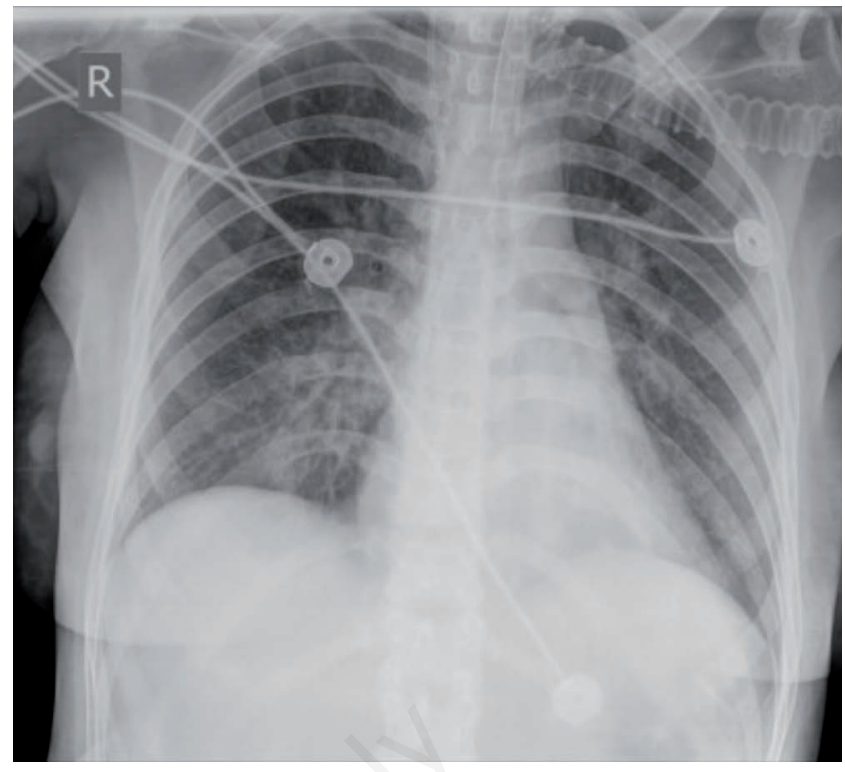

Figure 1. A-P portable chest $\mathrm{x}$-ray.
A

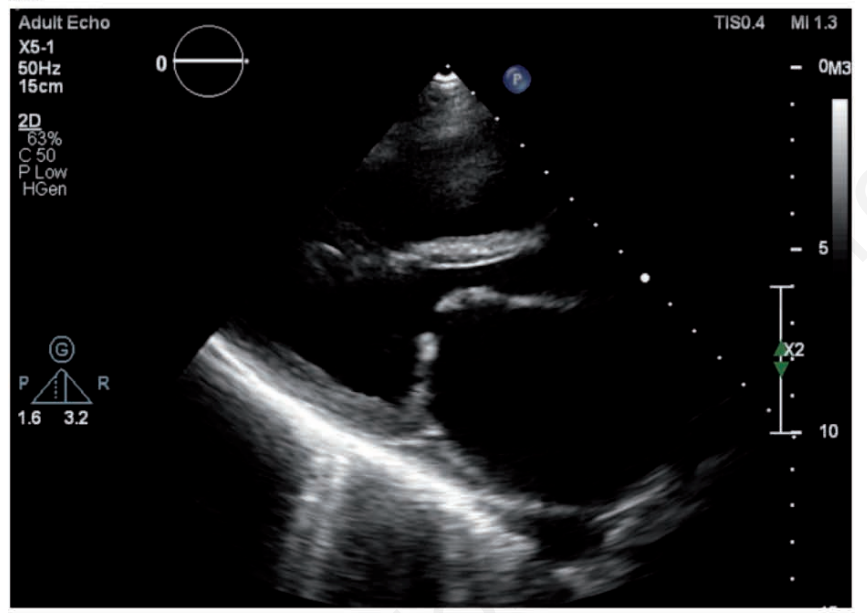

C

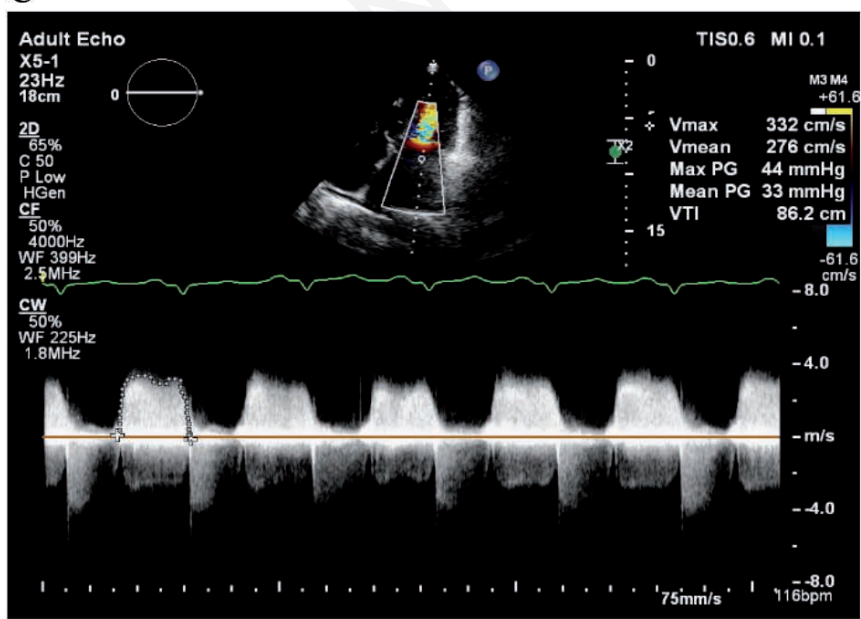

B

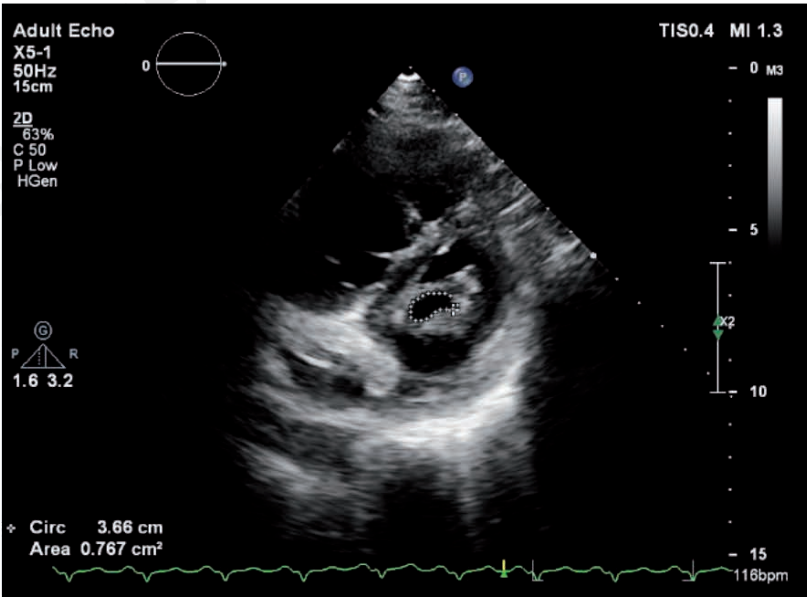

D

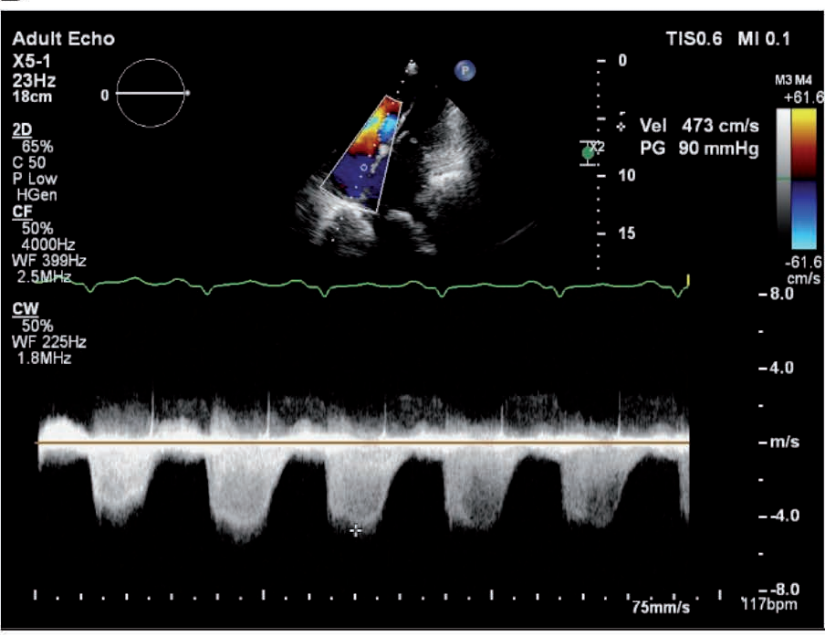

Figure 2. Transthoracic echocardiography before intervention, two dimensional (A-B) and Doppler signals (C-D) showing very severe rheumatic mitral stenosis with mean pressure gradient of $33 \mathrm{mmHg}$ and severe pulmonary hypertension. 

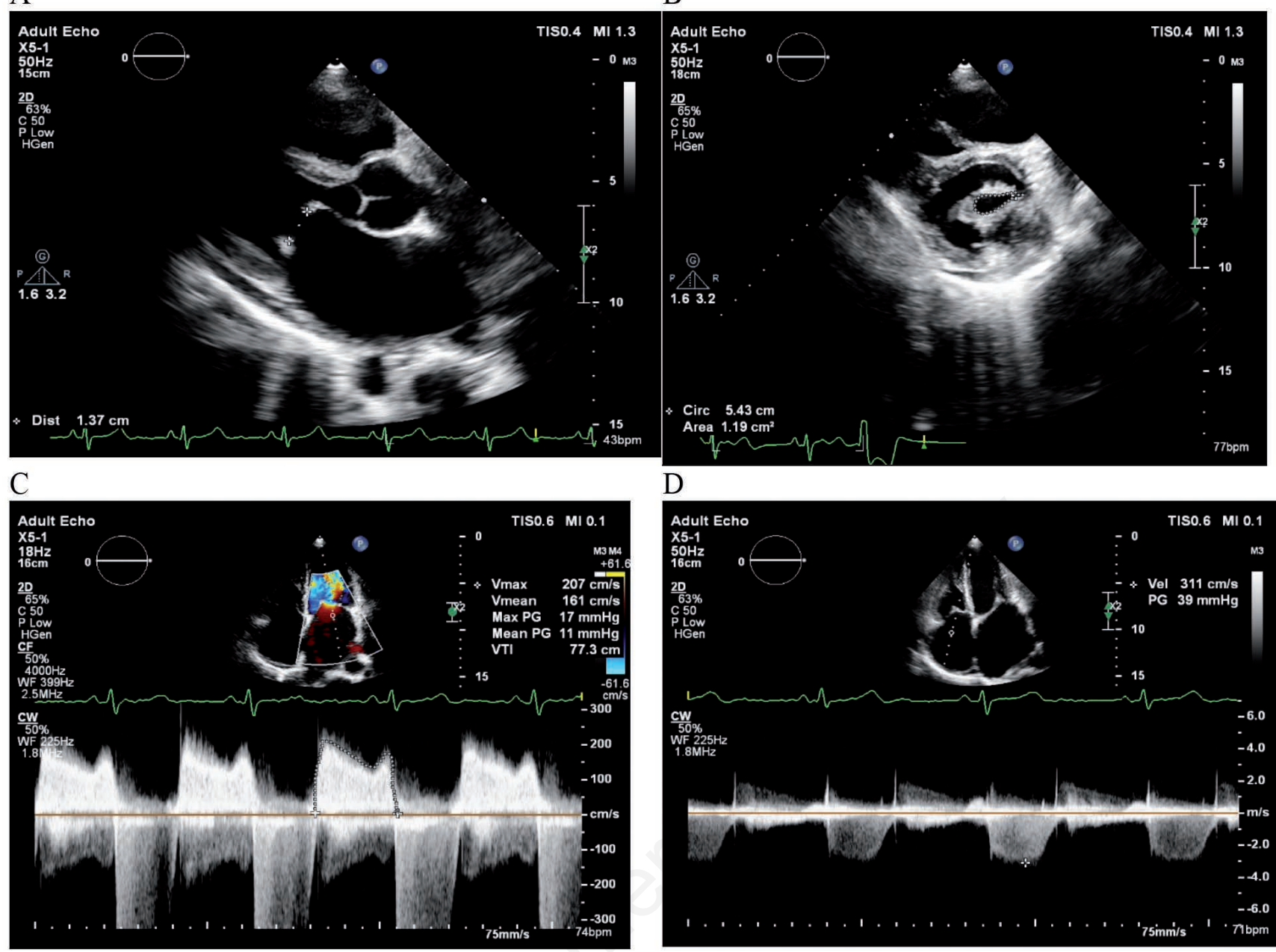

$\mathrm{D}$

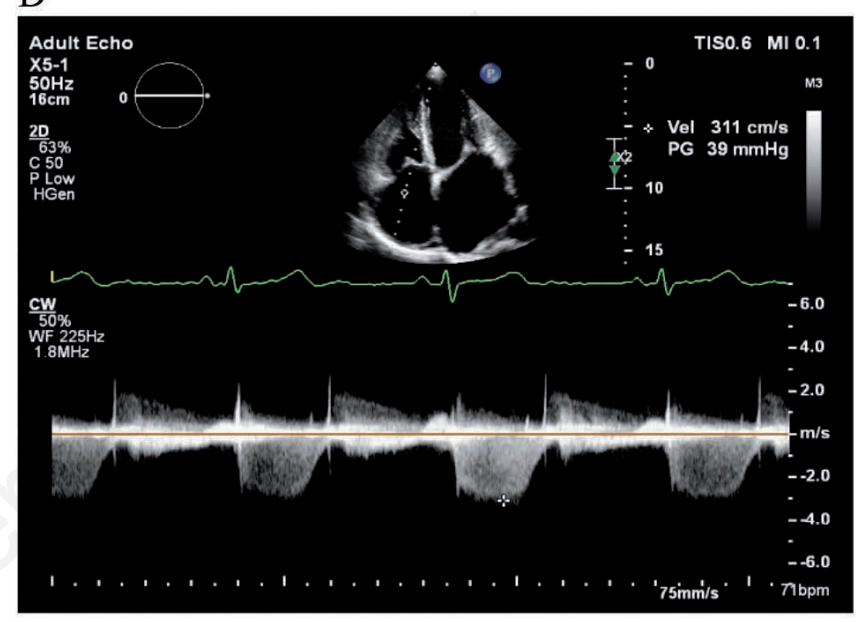

Figure 3. Echo study after PTMC, showing improvement in valve opening (A), increase in valve area(B), decrease in MPG of mitral valve (C), and pulmonary artery systolic pressure (D). MPG, mean pressure gradient.

hemoptysis. Mitral stenosis can lead to pulmonary hypertension with increased vascular hydrostatic pressure $[3,5]$. In addition, an increase in pulmonary venous pressure during mitral stenosis leads to a reverse blood flow from the pulmonary veins to the bronchial venous network; hence, this makes it possible as congested bronchial vasculature. Increased pressure causes vascular rupture and hemoptysis with the origin of pulmonary and bronchial arteries $[5,6]$. Massive aspiration of blood was probably an important factor, which caused asphyxiation and suddenly death [1]. In addition to medication, interventional procedures and or cardiac surgery are defined. Severe mitral stenosis could be candidates for percutaneous transluminal mitral commissurotomy (PTMC) when there is a suitable valvular anatomy [6]. The high rate of maternal and fetal mortality during surgery (1.8-33\%) led to the acceptance of PTMC in pregnant women as a lower risk and an alternative modality $[5,6]$.

\section{Conclusions}

We suggest that every physician in exposure to hemoptysis should consider heart disease and mitral valve stenosis. So, diagnosis of exact etiology in massive hemoptysis and pregnancy is worthwhile.

\section{References}

1. Korzan S, Jones E, Mutneja R, Grover P. Mitral stenosis due to rheumatic heart disease - A rare cause of massive hemoptysis. Respir Med Case Rep 2018;23:35-39.

2. Seedat UF, Seedat F. Post-primary pulmonary TB haemoptysis - When there is more than meets the eye. Respir Med Case Rep 2018;25:96-9.

3. Leung WH, Lau CP, Wong CK, Cheng CH. Fatal massive pulmonary hemorrhage complicating mitral stenosis. Clin Cardiol 1990;13:136-8.

4. Hodes RM. Hemoptysis in rheumatic heart disease. Trop Geogr Med 1992;44:328-30.

5. Aigner F, Speich R, Schuurmans MM. Prominent bronchial vasculature, hemoptysis, and bilateral ground-glass opacities in a young woman with mitral stenosis. J Bras Pneumol 2016;42:386

6. Firouzi A, Samiei N, Ahmadi S, et al. Percutaneous transluminal mitral commissurotomy in pregnant women with severe mitral stenosis. J Tehran Heart Cent 2019;14:12-7. 